\title{
Pistachio Oil
}

National Cancer Institute

\section{Source}

National Cancer Institute. Pistachio Oil. NCI Thesaurus. Code C107349.

The oil extracted from the fruit of Pistacia vera. Pistachio oil is used as a food oil. 